\title{
EFFICACY, TOLERABILITY AND SAFETY OF INTRAVENOUS IRON SUCROSE IN POSTPARTUM ANAEMIA
}

\author{
Rucha Rajput ${ }^{1}$, Ashish Podey ${ }^{2}$, Tushar Baheti ${ }^{3}$, Bangal VB ${ }^{4}$, Sarita Deshpande ${ }^{5}$ \\ ${ }^{1}$ III year Postgraduate resident, ${ }^{2}$ Assistant Professor, Department of ENT, ${ }^{3}$ Assistant Professor, Department of Pharmacology, \\ ${ }^{4}$ Professor \& HOD, ${ }^{5}$ Professor, Department of Obstetrics and Gynaecology, \\ Rural Medical College, Loni, Ahmednagar, MHS. India.
}

\begin{abstract}
Background: Anemia is one of major contributing factor in maternal mortality and morbidity in third world countries and according to the WHO, contributes to $40 \%$ maternal deaths. Postpartum anemia is observed in up to $27 \%$ of women. It is a common problem throughout the world. Treatment of postpartum iron deficiency anemia includes oral and parenteral iron supplmentaion as well as blood transfusion in severe cases. Methods: This was a prospective longitudinal study carried out in Department of Obstetrics \& Gynaecology of PRH, Loni. Total 80 women suffering from postpartum anemia of age above 18 years with haemoglobin (HB) level below $11 \mathrm{gm} / \mathrm{dl}$ and above 6 gm/dl were included for the study. After history taking, clinical examination and baseline $\mathrm{Hb}$ level, all of them were administered intravenous iron sucrose $200 \mathrm{mg}$ per dose per day till the total calculated dose was administered. The post therapy evaluation was done with the estimation of $\mathrm{Hb}$ on day 1 , day 7 , day 14 and day 21 . Results: $31.25 \%$ women belonged to the age group each of 19-21 years and 22-24 years. Maximum number of patients received 3 doses of IV Iron sucrose (i.e. total $600 \mathrm{mg}$ ) followed by 2 doses (i.e. total $400 \mathrm{mg}$ ), 4 doses (i.e. total $800 \mathrm{mg}$ ) and 5 doses (i.e. total $1000 \mathrm{mg}$ ) respectively. Hb level rises extremely significantly $(\mathrm{p}<0.001)$ after IV Iron Sucrose administration on day 1, 7, 14 \& 21 as compared to corresponding values before delivery as analyzed by Friedman Test (Nonparametric Repeated Measures ANOVA) . 16 patients (20\%) experienced thrombophlebitis to IV Iron Sucrose administration. About 12 (15\%) patients experienced rigor followed by sweating in 10 patients $(12.5 \%)$ and fever in 8 patients $(10 \%)$. About 62 patients $(77.5 \%)$ from total 80 reported well tolerability to IV Iron Sucrose while remaining 18 patients $(22.5 \%)$ reported poor tolerability to IV Iron Sucrose Conclusion: Intravenous iron sucrose increases the haemoglobin more rapidly in first week as compared to second and third week in women with postpartum iron deficiency anemia. Hypersensitivity reaction, chest pain, dyspnoea reported with iron dextran and iron sorbitol citric acid were not observed with iron sucrose. Intravenous iron sucrose can be used safely to fill a rift between blood transfusion and oral iron in treatment of postpartum iron deficiency anemia.
\end{abstract}

Keywords: Postpartum anemia; Iron Sucrose; Efficacy; Safety and tolerability of Iron Sucrose.

\section{INTRODUCTION}

Anemia is one of major contributing factor in maternal mortality and morbidity in third world countries and according to the $\mathrm{WHO}$, contributes to $40 \%$ maternal deaths. Postpartum anemia is observed in up to $27 \%$ of women [1]. It is a common problem throughout the world [2]. It is a major cause of maternal morbidity such as lethargy, headaches, tiredness, dizziness, lactation failure, and postpartum depression and mortality in resource poor countries[3,4] Depending on the grade of postpartum anemia, symptoms like reduced exercise performance, tiredness, headache, increased cardiovascular strain, higher risk for infections, and lactation problems occur [5]. Iron deficiency is the principle cause of anemia [6]. Iron deficiency anemia is very much prevalent in the tropics particularly amongst women of child bearing age, especially in under privileged sector. Nutrition of a woman in the family is always at bay because of various social and cultural prac-

DOI: $10.31878 / \mathrm{ijcbr} .2018 .51 .07$
eISSN: $2395-0471$
pISSN: $2521-0394$

tices and on top of it she always remains in the dark about her own health. To highlight this, there is a saying in the countryside that 'Gold is the metal she remembers and iron is the metal she forgets!'

High prevalence of iron deficiency is attributable to faulty dietetic habit, faulty absorption mechanism because of high prevalence of intestinal infestation and increased iron loss as consequence of repeated pregnancies at short intervals, excessive blood loss during menstruation, hookworm infestation and chronic malaria [7]. Irrespective of mode of delivery, blood loss is a contributing factor. Majority of anemic women are received directly in labour without having any chance of correcting anemia antenataly. Postpartum anemia is associated with longer hospital stays, depression, anxiety, and delayed infant development [8].

At the present time, there is no consensus on the management of postpartum anemia, and clinical practice varies from one clinic to another. The standard approach to treatment in the majority of institutions is oral supplementation, with blood transfusion reserved for more severe or symptomatic cases [9]. There are number of hazards of blood transfusion including transfusion of wrong blood, anaphylaxis and infections, any of which would be devastating for the young mother [10]. Oral iron is unreliable in treatment of severe anemia due to

Correspondence: Dr. Ashish Podey, Assistant Professor, Department of ENT, Rural Medical College, Loni, Ahmednagar. E-mail: tusharkgmu@yahoo.com

(C) Authors; 2019. International Journal of Clinical and Biomedical Research, Sumathi Publications.

This is an Open Access article which permits unrestricted non-commercial use, provided the original work is properly cited. 
its limited absorption and gastrointestinal side effects that affect compliance [3]. Parenteral iron therapy by intramuscular injection of iron dextran is a painful alternative with a variable degree of efficacy. Because of its site of administration and side effects, compliance is low. In practice the use of iron dextran is not generally recommended due to the unpredictable risk of lifethreatening or serious acute reactions in 0.6 to $2.3 \%$ of patients and the availability of safer agents [11-13]. Parental iron administration with ferrous sucrose is now available and can be used for treatment of iron deficiency anemia in postpartum period [14].

This study was proposed to carry out a prospective randomized study of intravenous iron sucrose in the treatment of postpartum anemia.

\section{MATERIALS AND METHODS}

Study design: An observational study.

Ethics approval: The study was approved by the institutional ethics committee and informed consent was obtained from the participants.

Study location: Department of Obstetrics and Gynaecology (OBGY) of Rural Medical College, Loni.

Study period: Study was carried out over the period of 2 years from $15^{\text {th }}$ Sep 2016 to $14^{\text {th }}$ June 2018.

Inclusion criteria: Total 80 Women suffering from postpartum anaemia aged 18 years or more with Hemoglobin of less than $10 \mathrm{~g} / \mathrm{dl}$ but more than $6 \mathrm{~g} / \mathrm{dl}$ at 24 to 48 hours after delivery who have treated with IV iron sucrose and those showing side effects to oral iron therapy were included in the study after written informed consent.

Exclusion criteria: Women who have received recent blood transfusion, Known cases of complications of pregnancy like eclampsia, heart disease etc where intensive monitoring is required or any other medical/ surgical complications and those with known allergy to parenteral Iron Sucrose were excluded from the study.

\section{Methodology:}

After careful history taking, clinical examination and minimal investigations other causes of anemia were ruled out. The initial iron status of the woman was assessed by the clinical and laboratory examinations (complete blood picture). The Haemoglobin ( $\mathrm{Hb}$ ) status of pregnant women who are clinically diagnosed with anemia was estimated by Sahli's acid- haematin method. $2 \mathrm{ml}$ of EDTA chelated blood from severely anaemic patients was sent for peripheral smear examination to the Central Lab, Rural medical hospital, Loni. Microcytic, hypochromic appearance of RBCs confirm IDA. The Hb status of the patients confirmed with IDA was documented.

Women having $\mathrm{Hb}$ levels less than $10 \mathrm{gm} / \mathrm{dl}$ at 24-48 hours post-delivery were included in the study. They were administered intravenous iron sucrose $200 \mathrm{mg}$ per dose per day till the total calculated dose was administered.

Iron sucrose was administered as an infusion in $250 \mathrm{ml}$ of $0.9 \%$ sodium chloride over a period of more than 30 minutes. Patients were monitored for 30 minutes for signs of intolerance such as anaphylactic reactions, skin rash, dyspnoea, facial flushing, metallic taste, urtricaria, hypotension, headache, chest pain, tachycardia, breathlessness etc. The treatment was stopped after the administration of total calculated dose and received no further iron supplementation. The post therapy evaluation was done with the estimation of $\mathrm{Hb}$ on day 1 , day 7, day 14 and day 21 .

Statistical analysis - Data analysis was done by using appropriate statistical methods.

\section{RESULTS}

The maximum number of women $28(35 \%)$ belonged to the age group of 25-27 years. $31.25 \%$ women belonged to the age group each of 19-21 years and 22-24 years. Only 2 women $(2.5 \%)$ were from age of 28 years. There were no women above 28 years of age (Table I).

Table 1. Age distribution in study population

\begin{tabular}{l|l|l}
\hline Age (yrs) & No. of women & \% \\
\hline $19-21$ & 25 & 31.25 \\
\hline $22-24$ & 25 & 31.25 \\
\hline $25-27$ & 28 & 35 \\
\hline 28 & 2 & 2.5 \\
\hline Total & 80 & 100 \\
\hline
\end{tabular}

Among 80 women, 44 (55\%) women were delivered by FTND (full term normal vaginal delivery) while remaining $36(45 \%)$ women were delivered by LSCS (lower segment Caesarean section).(Table 2)

Table 2. Mode of Delivery of Patients

\begin{tabular}{l|l|l}
\hline Mode of Delivery & $\begin{array}{l}\text { Number of } \\
\text { Patients } \\
(\mathbf{n = 8 0})\end{array}$ & $\mathbf{\%}$ \\
\hline FTND & 44 & 55 \\
\hline LSCS & 36 & 45 \\
\hline
\end{tabular}

Maximum number of women reported blood loss in the range of $751-1000 \mathrm{ml}(55 \%)$ followed by $450-750 \mathrm{ml}$ $(27.5 \%)$ and then $1001-1750 \mathrm{ml}(17.5 \%)$. (Table 3$)$

Table 3. Amount of Blood Loss during and after delivery

\begin{tabular}{l|l|l}
\hline $\begin{array}{l}\text { Blood Loss during } \\
\text { delivery (ml) }\end{array}$ & $\begin{array}{l}\text { Number of } \\
\text { Patients }\end{array}$ & \% \\
\hline $450-750$ & 22 & 27.5 \\
\hline $751-1000$ & 44 & 55 \\
\hline $1001-1750$ & 14 & 17.5 \\
\hline
\end{tabular}

Maximum number of patients received 3 doses of IV Iron sucrose (i.e. total $600 \mathrm{mg}$ ) followed by 2 doses (i.e. total $400 \mathrm{mg}$ ), 4 doses (i.e. total $800 \mathrm{mg}$ ) and 5 doses (i.e. total $1000 \mathrm{mg}$ ) respectively (Table 4) 
Table 4. Total number of doses of IV Iron Sucrose administered

\begin{tabular}{l|l|l}
\hline $\begin{array}{l}\text { Total Doses } \\
\text { administered } \\
\text { (One } \\
\text { dose=200mg) }\end{array}$ & $\begin{array}{l}\text { Number of Patients } \\
(\mathbf{n = 8 0})\end{array}$ & $\mathbf{\%}$ \\
\hline 2 & 25 & 31.25 \\
\hline 3 & 37 & 46.25 \\
\hline 4 & 14 & 17.5 \\
\hline 5 & 4 & 5 \\
\hline
\end{tabular}

$\mathrm{Hb}$ level rises extremely significantly $(\mathrm{p}<0.001)$ after IV Iron Sucrose administration on day $1,7,14 \& 21$ as compared to corresponding values before delivery as analyzed by Friedman Test (Nonparametric Repeated Measures ANOVA. Also Hb level rises extremely significantly $(\mathrm{p}<0.001)$ after IV Iron Sucrose administration on day $7,14 \& 21$ as compared to corresponding values on Day 1 as analyzed by Friedman Test (Nonparametric Repeated Measures ANOVA). However there is no statistically significant difference in Mean $\mathrm{Hb}$ values observed between Day 7 and Day 14 as well as between Day 7 and Day 21. Also, Mean $\mathrm{Hb}$ values between Day 14 \& Day 21 did not differ significantly from each other.

16 patients $(20 \%)$ experienced thrombophlebitis to IV Iron Sucrose administration. About $12(15 \%)$ patients experienced rigor followed by sweating in 10 patients $(12.5 \%)$ and fever in 8 patients $(10 \%) .4$ patients $(5 \%)$ suffered from nausea, $3(3.75 \%)$ from vomiting and 2 $(2.5 \%)$ from flushing after IV Iron Sucrose administration. (Table 5)

Table 5. Adverse effects reported to IV Iron Sucrose administration

\begin{tabular}{l|l|l}
\hline Adverse Effects & Number & $\mathbf{\%}$ \\
\hline Fever & 8 & 10 \\
\hline Rigors & 12 & 15 \\
\hline chest pain & 0 & 0 \\
\hline Dyspnoea & 0 & 0 \\
\hline Flushing & 2 & 2.5 \\
\hline Sweating & 10 & 12.5 \\
\hline Nausea & 4 & 5 \\
\hline Vomiting & 3 & 3.75 \\
\hline Thrombo-phlebitis & 16 & 20 \\
\hline Total & 55 & 100 \\
\hline
\end{tabular}

About 62 patients (77.5\%) from total 80 reported well tolerability to IV Iron Sucrose while remaining 18 patients $(22.5 \%)$ reported poor tolerability to IV Iron Sucrose. (Table 6)

Table 6. Tolerability to IV Iron Sucrose administration

\begin{tabular}{l|l}
\hline Tolerability & N (\%) \\
\hline Well & $62(77.5 \%)$ \\
\hline Poor & $18(22.5 \%)$ \\
\hline
\end{tabular}

\section{DISCUSSION}

Iron deficiency anemia in pregnancy is a global public issue, affecting an estimated $41.8 \%$ of the pregnant women (Mclean et al 2008) [15]. It is associated with increased risk for low birth weight, preterm delivery, maternal and perinatal morbidity and mortality globally, especially in low resource settings $[16,17]$

Current UNICEF/WHO recommendations for the prevention and treatment of anemia in pregnancy state that, where prevalence of anemia is $<40 \%$; mothers should receive $60 \mathrm{mg}$ of iron plus $400 \mu \mathrm{g}$ of folic acid every day for 6 months in pregnancy and where prevalence is $>40 \%$; mothers should receive this dose, continuing to 3 months post partum.

In the present study we investigated efficacy of IV Iron sucrose administration after comparing $\mathrm{Hb}$ values at different times and also found out the safety and tolerability to IV Iron sucrose.

While studying the distribution of anemia in various age groups in present study, the median age was 23 years. All study subjects were between 19-28 years (Table I). In some studies investigators had not found any significant difference in the age on anemic and nonanemics women(Amy et al 2000, Geelhoed et al 2006) [18, 19] but one study had found significant difference of age in the studied population (Peterson et al) [20] where the mean age of anemic population was $25.8+5.6$ ( $\mathrm{p}$ value 0.017 ). Women with less than 20 years of age were $6.25 \%$ in the present study. Thus percentage of teenage pregnancy is low indicating that teenage pregnancy is showing a decreasing trend in our rural area. When we compared our teenage pregnant population with the other study, the figures were much less compared to the other rural study population (Geelhoed et al) [19] in which $22.9 \%$ women were of age less than 20 with the mean $\mathrm{Hb}$ levels less than $8 \mathrm{gm} \%$.

While comparing the mode of delivery in the present study, $44(55 \%)$ patients included in the study had undergone full term normal vaginal delivery while 36 $(45 \%)$ underwent casarean delivery. During the literature search we could found no evidences to correlate maternal anemia and the mode of delivery.

In our study, maximum number of women reported blood loss in the range of $751-1000 \mathrm{ml}(55 \%)$ followed by $450-750 \mathrm{ml}(27.5 \%)$ and then $1001-1750 \mathrm{ml}(17.5 \%)$ but none required blood transfusion as all three women were clinically and hemodynamically stable. All these women were managed with IV Iron sucrose administration.

Iron sucrose is a high molecular weight complex of iron hydroxide with sucrose that on i.v. injection is taken up by RE cells, where iron dissociates and is utilized. It is safer than the older formulations and a dose of $100 \mathrm{mg}$ ( $\max 200 \mathrm{mg}$ ) can be injected i.v. taking $5 \mathrm{~min}$, once daily to once weekly till the total calculated dose (including that to replenish stores) is administered.

In our study, we have given IV Iron sucrose $200 \mathrm{mg}$ once daily to all patients till the total calculated dose was administered. The iron sucrose complex was administered first and was diluted in $250 \mathrm{~mL} 0.9 \%$ sodium chloride, followed by $5 \mathrm{~mL}$ saline to flush iron particles from the tubing. The formula for calculating total 
iron requirement is

Iron requirement $(\mathrm{mg})=4.4 \times$ body weight $(\mathrm{kg}) \times \mathrm{Hb}$ deficit $(\mathrm{g} / \mathrm{dl})$

Maximum number of patients received 3 doses of IV Iron sucrose (i.e. total $600 \mathrm{mg}$ ) followed by 2 doses (i.e. total $400 \mathrm{mg}$ ), 4 doses (i.e. total $800 \mathrm{mg}$ ) and 5 doses (i.e. total $1000 \mathrm{mg}$ ) respectively.

$\mathrm{Hb}$ level rises extremely significantly $(\mathrm{p}<0.001)$ after IV Iron Sucrose administration on day $1,7,14 \& 21$ as compared to corresponding values before delivery as analyzed by Friedman Test. This indicated that maximum increase in $\mathrm{Hb}$ level occurred in first week while in second and third week, rise in $\mathrm{Hb}$ level is not that too fast as iron may be utilized to replenish the lost body stores.

Study performed by Krafft et al [21] had also found efficacy of IV iron sucrose in patients of postpartum anemia. $\mathrm{Hb}$ level rises from baseline $7.5 \mathrm{gm} / \mathrm{dl}$ to mean $10.5 \mathrm{gm} / \mathrm{dl}$ in 20 women after 15 days of IV iron sucrose administration.

Safety analysis of IV iron sucrose administration revealed that it was safer molecule as compared to earlier iron dextran and other compounds. No patient experienced chest pain and dyspnoea while only 2 patients suffered from flushing which was common with Iron dextran and Iron Sorbitol citric acid. These results were highly encouraging for Gynaecologists and general practitioners as they can safely give iron sucrose in treatment of iron deficiency anemia. Only significant adverse effects reported were thrombophlebitis, rigors, fever and sweating which can be avoided by giving it slowly IV in diluted normal saline.

Tolerabilty analysis to IV iron sucrose administration revealed that about 62 patients $(77.5 \%)$ from total 80 reported well tolerability while remaining 18 patients $(22.5 \%)$ reported poor tolerability to IV Iron Sucrose.

\section{CONCLUSION}

Intravenous iron sucrose increases the haemoglobin more rapidly in first week as compared to second and third week in women with postpartum iron deficiency anemia. So, IV iron sucrose is well efficacious in the treatment of postpartum anemia. Hypersensitivity reaction, chest pain, dyspnoea were not observed with iron sucrose so Iron sucrose should be considered safe treatment in postpartum anemia. About $77.5 \%$ women reported good tolerability to IV Iron sucrose so it should also be considered well tolerated option.

Intravenous iron sucrose should be considered efficacious, safe and well tolerable option to fill a rift between blood transfusion and oral iron in treatment of postpartum iron deficiency anaemia.

\section{REFERENCES}

1. Gary F. Cunningham, Hematological Disorders, William's Obstetrics, McGraw Hill, $22^{\text {nd }}$ edition p. 1144 , 1145.

2. Atkinson L, Baxley E. Postpartum fatigue. Am Fam Physician.1994;50(1):113-8.

3. Ekanem A, Etuk S, Samson-Akpan U. The influence of cultural practice on puerperal anemia. Int J Gynecol Obstet. 1996;55: 169-70.
4. Harrison K. Maternal mortality in developing countries. Br J Obstet Gynaecol. 1989;96:1-3.

5. Dunne JR, Malone D, Tracy JK. Perioperative anemia: an independent risk factor for infection, mortality, and resource utilization in surgery. J Surg Res 2002;102: 237 44.

6. Fernando Arias, Practical guide to high risk pregnancy and delivery, $2^{\text {nd }}$ edition, p. 245.

7. Dutta DC. Medical illness complicating pregnancy. Textbook of Obstetrics, $6^{\text {th }}$ edition. [Ed Konar H] The central Book Agency Pvt Ltd. Culcutta: 2004; p262-271.

8. Seid, Melvin H. Derman, Richard JBaker, Jeffrey B. Banach, Warren Goldberg, Cynthia Rogers, Ralph. Ferric carboxymaltose injection in the treatment of postpartum iron deficiency anemia: a randomized controlled clinical trial. Am J Obstet Gynecol; 2008: 199(4):435e1-e7.

9. Bhandal N, Russell R. intravenous versus oral iron therapy for postpartum anemia. BJOG 2006;DOI:10.1111/ j.1471-0528.2006.01062.

10. DeGruchy's clinical hematology in clinical practice. Hypochromic anemias: Iron deficiency and Sideroblastic. [eds. Firkin F, Perington D, Rush B, Chesterman C.] Blackwell Science Publication. Fifth edition. 1989. p 3160.

11. Burns DL, Mascioli EA, Bistrian BR. Parenteral iron dextran therapy: a review. Nutrition 1995; 11: 163-8.

12. Fishbane S, Ungureanu VD, Maesaka JK. The safety of intravenous iron dextran in hemodialysis patients. Am.J.Kidney Dis. 1996; 28: 529-34.

13. Hamstra RD, Block MH, Shocket AL. Intravenous iron dextran in clinical medicine. JAMA 1980:243:1726-31.

14. Scott B. Silverstein, George Rodgers-Parenteral iron therapy options; American Journal of Hematology 2004;76:74-78

15. McLean E, CogswellM, Egli I, Wojdyla D, de Benoist B. worldwide prevalence of anemia, WHO Vitamin and Mineral Nutrition Information System, 1993-2005. Public Health Nutr 2008;1-11.

16. Brabin J, Hakimi M, Pelletier D. An analysis of anemia and pregnancy related maternal mortality. J Nutr 2001; 131 (2S-2): 604S-24S; discussion 614S-615S.

17. Pena-Rosas JP, Viteri FE. Effects of routine oral iron supplementation with or without folic acid for women during pregnancy. Cochrane Database Syst Rev 2006;3: CD004736

18. Amy L, Terhune F, Cogswell ME, Khan LK, Will JC, Ramakrishnan U. Iron deficiency anemia: higher prevalence in Mexican American than in non-Hispanic white females in the third National Health and Nutrition Examination Survey. Am J Clin Nutr 2000; 72:963-8.

19. Geelhoed D, Agadzi F, Visser J, ablordeppey E, Asare K, O'rourke P, Van JS, \& Jos van roosmalen L. Severe anemia in pregnancy in rural Ghana: a case-control study of causes and management. Acta Obstetricia et Gynecologica. $2006 ; 85: 1165-71$.

20. Peterson LA, Lindner DS, Charmaine BSM, Kleiber RNM. Zimmerman B, Almira T, Hinton RN, Yankowich J. Factors that predict low hematocrit levels in the postpartum patients after vaginal delivery. Am J Obset Gynecol 2002; 186:4:737-44.

21. Krafft, A; Breymann, C. Iron sucrose with and without recombinant erythropoietin for the treatment of severe postpartum anemia: A prospective, randomized, openlabel study. Journal of Obstetrics and Gynaecology Research 2011;37(2):119-24. 